\title{
HIGH APPARENT CREEP ACTIVATION ENERGIES IN MUSHY ZONE MICROSTRUCTURES
}

\author{
Jean-Marie Drezet, Gunther Eggeler \\ Materials Science Department, Swiss Federal Institute of Technology \\ $\mathrm{CH}-1015$ Lausanne, Switzerland \\ (Received December 21, 1993) \\ (Revised May 16, 1994)
}

\section{Mechanical data characterizing mushy zone microstructures}

Modelling represents an important tool in modern material processing which no longer follows the traditional trial and error route but rather represents what may be termed a right first time technology [1]. To successfully model technological solidification processes, thermodynamic and kinetic data are required. But mechanical aspects are important as well [2]: during solidification, temperature gradients or mechanical constraints imposed by the mold result in solidification stresses. These stresses must be considered for at least the following two reasons: first, they can lead to local air gap formation between metal and mold thus changing heat extraction, cooling rate and finally the cast microstructure [3]; second, at a larger scale they may influence the final product shape [4]. Moreover, they can assist in cavity formation and can produce cracking. Such stresses become important as soon as a significant amount of solid phase has formed during solidification. In principle, these stresses can be calculated using viscoelastic finite element stress analysis [5]. But, finite element calculations require as an input the constitutive law which governs the mechanical behavior. Therefore, there is an interest in mechanical data of solidifying alloys with mushy zone microstructures: Ackermann and Kurz [6] investigated the mechanical properties of a solidifying Al$\mathrm{Mg}$ alloy perpendicular to the growth axis of the columnar crystals. The tensile behavior of solidifying Al-Cu alloys was studied by Wisniewski [7] and recently, Branswyck [8] proposed a modified indentation test which, in combination with FEM analysis, yields quantitative flow rules. Nevertheless, there is still a need for more mechanical data of solidifying alloys, especially creep data - where strain accumulates at a constant stress - only rarely exist for processing conditions.

Creep data are generally available for temperatures far below the melting point. One way of obtaining input data for process modelling is to use constitutive equations established on the basis of low temperature data and extrapolate to solidification temperatures. For creep one can use the well established equation for the minimum creep rate

$$
\varepsilon_{m 1 n}=A \cdot \sigma^{n} \cdot \exp \left(-\frac{Q}{R \cdot T}\right)
$$

where $A$ is a constant, $\dot{\varepsilon}_{\min }$ is the minimum creep rate, $Q$ represents the apparent creep activation energy and $R$ and $T$ are universal gas constant and temperature, respectively. However, mechanical data which are obtained by such an extrapolation do not appropriately reflect the mechanical behavior of mushy zone microstructures [9]. In this work, we present creep data for mushy zone microstructures of aluminum alloys. In the evaluation of the creep data, we focus on the temperature dependence of the minimum creep rate.

\section{Material, experiments and mechanical results}

The chemical composition of the two aluminum alloys investigated in the present study (referred to as AA1201 and AA3104) are given in Table 1. Large ingots were cast using these grainrefined alloys in a direct chill continuous casting ('DCC') process [10]. From these alloys, standard creep specimens with a $40 \mathrm{~mm}$ gauge length and a $8 \mathrm{~mm}$ diameter were machined and tested at constant 
load in high resolution creep machines at temperatures ranging from $300^{\circ}$ to $645^{\circ} \mathrm{C}$, and at stresses between 0.25 and $30 \mathrm{MPa}$. The objective of this work was to obtain mechanical data which could be used as an input for FEM calculations of stresses and strains in the DCC process.

\begin{tabular}{|c|c|c|c|c|}
\hline Alloy/Element & Fe & Sl & Mq & Mn \\
\hline AA1201 & 0.41 & 0.14 & 0.012 & 0.018 \\
\hline AA3104 & 0.46 & 0.22 & 1.14 & 1.04 \\
\hline
\end{tabular}

Iable 1: Composition (\% wt) of the two aluminum alloys investigated in the present study.

Figures $1 \mathrm{a}$ and $1 \mathrm{~b}$ show creep results obtained for alloy $\mathrm{AA1201}$ at $640^{\circ} \mathrm{C}$. From such tests, the stress dependence of the minimum creep rate was determined as shown in Figures $2 a$ and $2 b$ for alloys AA1201 and AA3104, respectively. The stress exponent $n$ decreases with increasing temperature for both alloys. Figures $3 a$ and $3 b$ show the temperature dependence of the minimum creep rates for alloys AA1201 and AA3104, respectively; the values of creep rates at low temperatures were obtained by extrapolation from higher stress data. For both alloys, the apparent activation energies for creep increase with increasing temperature. It is striking that for alloy AA1201 the measured apparent creep activation energy increases rapidiy with temperature above $620^{\circ} \mathrm{C}$. For alloy AA3104, the apparent activation energy increases from $800 \mathrm{~kJ} / \mathrm{mol}$ below $600^{\circ} \mathrm{C}$ to $2525 \mathrm{~kJ} / \mathrm{mol}$ above this temperature. These values are much higher than activation energy values which can be rationalized on the basis of diffusion assisted climb processes which control creep of pure metals and single phase alloys [11-13].

Figure 4 shows the microstructure of alloy AA3104 after creep testing at $625^{\circ} \mathrm{C}$ and waterquenching. The former liquid phase transforms into a fine eutectic microstructure which appears between the primary phase dendrites.

\section{Ratlonalization of high apparent creep activation energies}

A hypothetical binary phase diagram: In order to explain the high apparent creep activation energies (Figure 3), we consider a simple binary eutectic system which is shown in Figure 5 . The coordinates of this diagram are given in Table 2. In this phase diagram, we consider three values of concentration: $c_{a}(2.4 \%)$ which is far from the eutectic concentration, $c_{c}(11.5 \%)$ which is near the eutectic concentration and $c_{b}(8.5 \%)$. These three concentrations will allow us to consider the influence of the alloy composition on creep behavior with special emphasis placed on the role of the part of the microstructure which is eutectic.

\begin{tabular}{|c|c|c|}
\hline coordinate & temperature $/{ }^{\circ} \mathrm{C}$ & concentration $/ \%$ \\
\hline melting point of pure A & $650\left(\mathrm{~T}_{\mathrm{m}}\right)$ & 0 \\
\hline maximum solubility of B in A & $600\left(\mathrm{~T}_{\mathrm{e}}\right)$ & $4\left(\mathrm{c}_{1}\right)$ \\
\hline eutectic reaction & $600\left(\mathrm{~T}_{\mathrm{e}}\right)$ & $15\left(\mathrm{c}_{2}\right)$ \\
\hline
\end{tabular}

Iable 2: Coordinates of the hypothetical binary system schematically illustrated in Figure 5.

Calculation of the amount of solid phase in the solid/liquid-region [14]: Under thermodynamic equilibrium, the relative amount of the solid phase - $f_{S}(T) \cdot$ in the solid-liquid region, is given by the lever rule

$$
f_{s}(T)=\frac{1}{1-k} \cdot \frac{\left(T_{11 q u}-T\right)}{\left(T_{m}-T\right)}
$$

where $T_{\text {liqu }}$ represents the concentration-dependent liquidus temperature, $T_{m}$ is the melting point of pure $A$ and $k$ is the distribution coefficient which is obtained as the ratio between the solid concentration $c_{s}$ and the liquid concentration $c_{/}[15]$. For the binary diagram schematically illustrated in Figure 5, the equilibrium value of this distribution coefficient was 0.27 . 


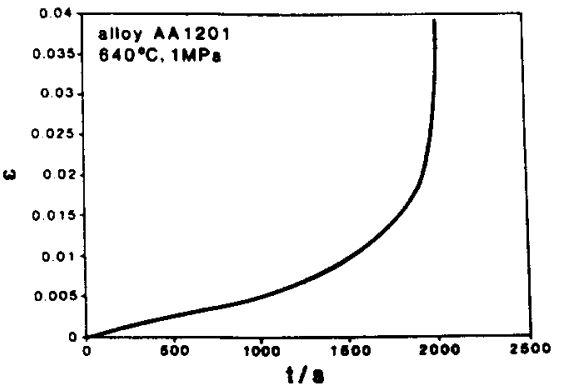

Eloure 1a: Creep strain as a function of time for alloy AA1201 $\left(640^{\circ} \mathrm{C}, 1 \mathrm{MPa}\right)$.

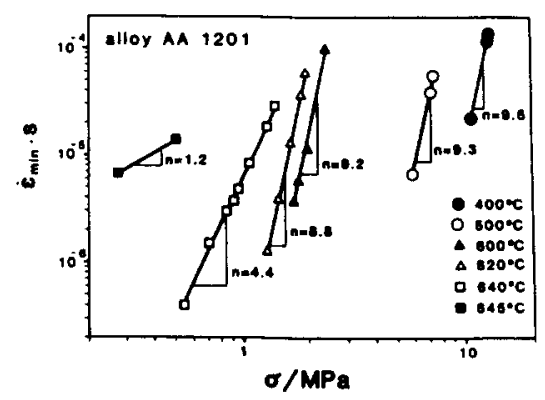

Eiqure 2a: Stress dependence of minimum creep rate for alloy AA1201.

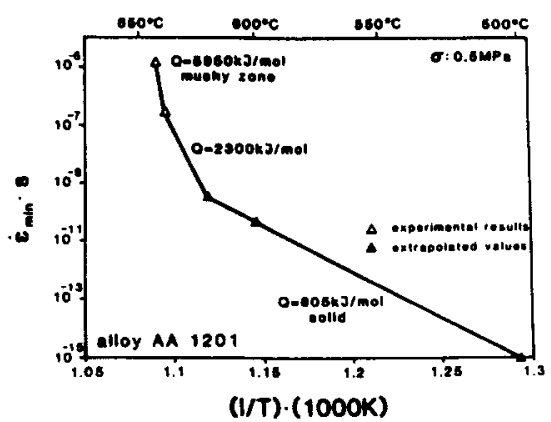

Einure 3a: Temperature dependence of minimum creop rate (AA1201).

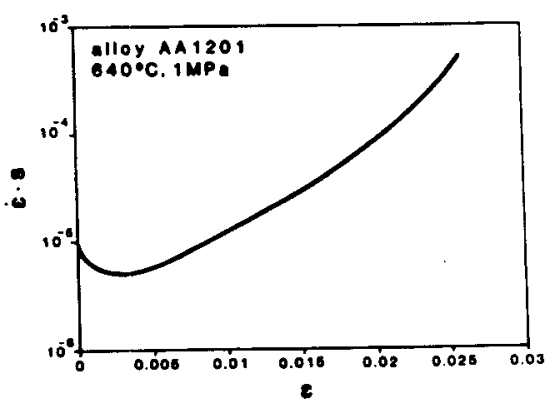

Fioure 1b: Creep rate as a function of strain for alloy AA1201 $\left(640^{\circ} \mathrm{C}, 1 \mathrm{MPa}\right)$.

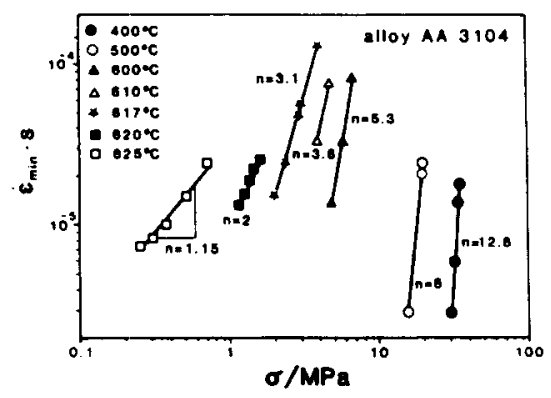

Fiaure 2b: Stress dependence of minimum creep rate for alloy AA3104.

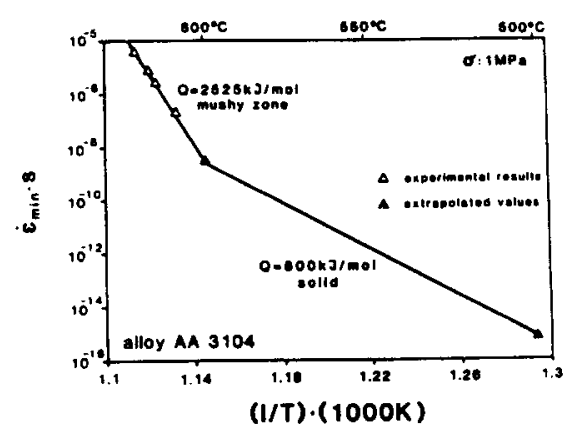

Eipure 3b: Temperature dependence of minimum creep rate (AA3104). 


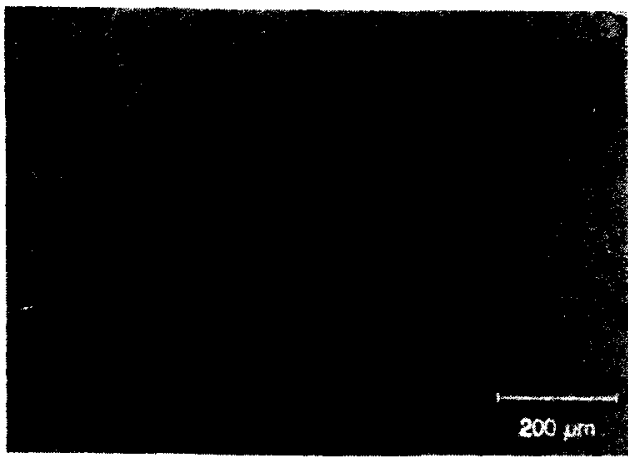

Eigure 4: Two phase microstructure of alloy AA3104 after quenching from $625^{\circ} \mathrm{C}$.

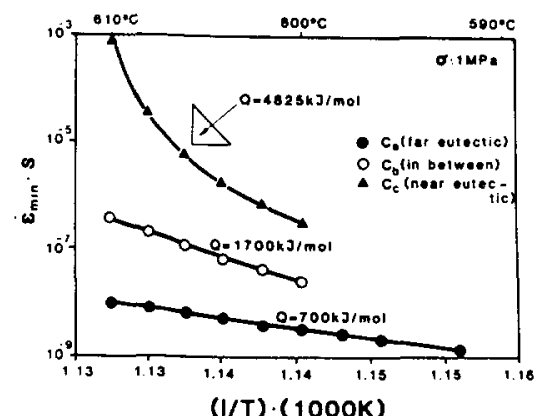

Eloure 6a: Temperature dependence of the minimum creep rate for $C_{A}, C_{B}$ and $c C$. $f_{S}(T)$ values from Equation 2.

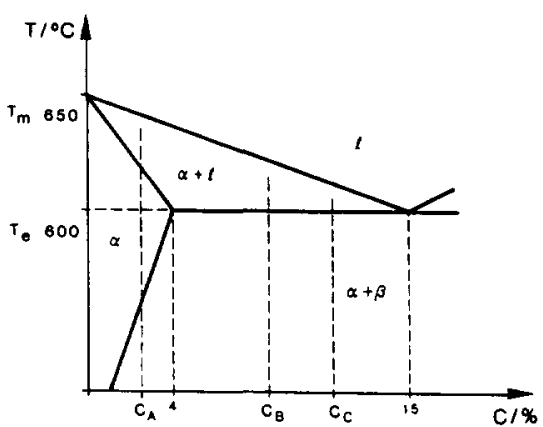

Eloure 5: Hypothetical binary phase diagram.

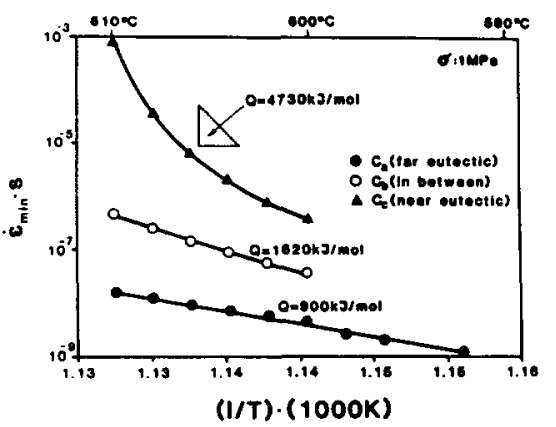

Eiqure 6b: Temperature dependence of the minimum creep rate.for $C_{A}, C_{B}$ and $C_{C}$. $f S(T)$ values from Equation 3.

The results presented in Figures $6 \mathrm{a}$ and $6 \mathrm{~b}$ clearly show that mechanical data for mushy zone microstructures with a low volume fraction of liquid phase can not be obtained by simply extrapolating lower temperature solid state data. Based on a simple solid-liquid model of the mushy zone microstructure, unusually high values of apparent creep activation energies can be rationalised. Activation energy values depend on (i) the phase diagram, (ii) the temperature, (iii) the alloy composition and (iv) on whether or not non-equilibrium phases are present. The results obtained using the simplified model outlined above are in good qualitative agreement with the experimental data, Figures $3 a$ and $3 b$.

\section{Discussion, summary and conclusions}

In the present work, creep data for mushy zone microstructures with a large fraction of solid phase are reported. Very high values of apparent creep activation energies were observed (Figures $3 a$ and 3b). A simple solid-liquid model was proposed in which the relative amount of solid - which carries all of the load - depends on the solidification conditions and is given by the lever rule (Equation 2) or the Scheil model (Equation 3). This model can help to explain the extremely high values of apparent creep activation energies in mushy zone microstructures. Straub and Blum do not observe such high values of apparent creep activation energles in single phase high purity aluminum 
The microstructure of an alloy with a concentration smaller than the eutectic concentration but larger than the maximium solubility of B in A consists of $\alpha$-phase particles surrounded by $\alpha / \beta$-eutectic. When heating such an alloy above $T_{e}$, the eutectic regions will melt.

During casting, diffusion is generally not fast enough to establish equilibrium conditions in a relatively short period and thus Equation 2 should not be applied. A better description of the amount of solid phase in the two phase region was proposed by Scheil [16] for the case of a solidifying alloy:

$$
f_{S}(T)=1-\left(\frac{T_{m}-T}{T_{m}-T_{1 \text { iqu }}}\right)^{\frac{1}{k-1}}
$$

Equation 3 allows for the formation of eutectic microstructure even for alloy concentrations like $c_{A}$ (Figure 5), which are lower than the maximum solubility of $B$ in $A$ (Table 2). During creep, this eutectic regions will transform into liquid phase at temperatures above $T_{e}$.

A simplified model of creep in mushy zone microstructures: We now introduce a simple solidliquid model of the mushy zone microstructure for low volume fractions of liquid. In this model, the liquid part of the mushy zone microstructure fully unloads and stresses are transferred to the remaining solid. The load carrying cross section perpendicular to the direction of the applied stress is given by $S_{O} \cdot f_{S}(T)$, where $S_{O}$ is the cross section of the entire sample and $f_{S}(T)$ is the volume fraction of solid given either by Equation 2 (thermodynamic equilibrium) or by Equation 3 (Scheil approach). The load carrying cross section decreases as the amount of liquid in the two phase region increases. It is now assumed that solid state creep does not depend on concentration, i.e. at temperatures below $T_{\theta}$ the three alloy compositions, $c_{a}, c_{b}$ and $c_{c}$, show the same creep behavior. This creep behavior is represented by Equation 1 using the set of parameters $A, n$ and $Q$ which is given in Table 3 .

\begin{tabular}{|c|c|}
\hline creep parameters & value \\
\hline A $\left[\mathrm{MPa}^{-4} / \mathrm{s}\right]$ & $2.3 \cdot 10^{33}$ \\
\hline $\mathbf{n}$ & 4 \\
\hline $\mathbf{Q}[\mathrm{kJ} / \mathrm{mol}]$ & 700 \\
\hline
\end{tabular}

Iable 3: Creep parameters used in the calculations for solid state creep.

During creep above the eutectic temperature, the mushy zone microstructure forms and the solid cross section decreases. The creep rate is then obtained as

$$
\dot{\varepsilon}_{m i n}=A \cdot\left(\frac{\sigma_{0}}{f_{s}(T)}\right)^{n} \cdot \exp \left(-\frac{Q}{R \cdot T}\right)
$$

$\sigma_{0}$ is the applied stress which was chosen as $1 \mathrm{MPa}$ in our calculations. In a first step, minimum creep rates where calculated from Equation 4 using an equilibrium $t_{S}(T)$-value, Figure $6 a$. It can be clearly seen that the apparent creep activation energy for the mushy zone microstructure is much higher than the apparent creep activation energy in the solid state. This apparent activation energy increases with temperature and its value is strongly dependant on alloy composition. At composition $C_{A}$ the alloy is solid at temperatures just above $T_{\theta}$ and the apparent creep activation energy does not depend on temperature below $T_{\theta}$. For alloy compositions $\mathrm{C}_{\mathrm{B}}$ and $\mathrm{C}_{\mathrm{C}}$, significantly higher apparent creep activation energies are obtained at temperatures just above $T_{\theta}$; this is simply due to the fact that parts of the alloys are now liquid and do not carry load.

For the low concentration alloy (composition $\mathrm{CA}_{A}$ ), this effect is even more pronounced when using the more realistic $f S(T)$-values defined by Equation 3 . Figure $6 \mathrm{~b}$. In this case, the alloy of composition $C_{A}$ contains a fraction of eutectic phase that melts at $T_{\theta}$. Thus, the solid fraction is less than one at temperatures just above $T_{e}$ - contrary to the equilibrium case (Equation 2) - and the apparent creep energy is higher $(900 \mathrm{~kJ} / \mathrm{mol}$ in this case against $700 \mathrm{~kJ} / \mathrm{mol}$ in the equilibrium case). For higher concentrations, Scheil's correction does not significantly influence the results. 
tested in the same temperature range [11]. In binary eutectic alloys, the large increase in apparent creep activation energy at temperatures just above the eutectic temperature is mainly due to the fact that in the solid-liquid region the area of the load carrying solid cross section decreases.

Modelling results are in good qualitative agreement with the experimental data. Figures 3a and $3 \mathrm{~b}$ for the two aluminum alloys AA1201 and AA3104. Reality is probably more complex. Thus it must be expected, that even before significant parts of the solid melt, the rate of grain boundary sliding will have increased greatly, possibly due to the formation of a liquid grain boundary phase. Enhanced creep rates in the solid-liquid region can be explained by the fact that the liquid may act as a lubricant allowing the grains of the materials to slide over each other more easily, or, that the liquid may provide a high diffusivity path, allowing diffusional transport away from load-bearing points or surfaces, very much as grain-boundary diffusion does during Coble creep. This is in agreement with the low stress exponent which is found just below the eutectic temperature (Figures $2 a$ and $2 b$ ). Pharr and Ashby [17] proposed a coupled-plasticity-plus-dissolution model in which the role of the liquid was to reduce the section of the necks, by dissolution, until the local stress there became large enough to cause another increment of plasticity or creep. It is believed that such a more realistic microstructural scenario - while much more difficult to model - will influence the apparent creep activation energy in a similar way, as the simple solid-liquid model outlined above.

\section{Acknowledgement}

Financial support by Alusuisse and the Swiss government under contract CERS 2496 is greatfully acknowledged. The authors wish to thank P. Musso for his help with the creep testing.

\section{References}

1. T.B. Gibbons, in: Advanced Materials and Processes, Proceedings of the First European Conference on Advanced Materials and Processes, EUROMAT 89, editors: H.E. Exner, V.Schuhmacher, DGM Informationsgesellschaft, Aachen 1990, pp.315-325

2. B.G. Thomas, in: Modelling of casting, welding and advanced solidification processes 6 , edited by T.S. Piwonka, V. Voller and L. Katgerman, The minerals, metals \& materials society. Warrendale, PA 1993, pp.519-534

3. Y. Nishida, W. Droste and S. Engler, Met. Trans., Vol.17B, Dec. 1986, pp.833-844

4. J.M. Drezet, B. Carrupt and M. Plata: Experimental study of ingot deformation during direct chill casting of Aluminum alloys; to be published in Met. Trans. B

5. M. Bellet, M. Menaï and F. Bay, in: Modelling of casting, welding and advanced solidification processes 6 , edited by T.S. Piwonka, V. Voller and L. Katgerman, The minerals, metals \& materials society, Warrendale, PA 1993, pp.561-568

6. P. Ackermann and W.Kurz, Materials science and engineering, 75 (1985) pp. $79-86$

7. P. Wisniewski and H.D. Brody, in: Modelling of casting, welding and advanced solidification processes 5, edited by M. Rappaz, M.R. Ozgu and K.W. Mahin, The minerals, metals \& materials society, Warrendale, PA 1991, pp.273-278

8. O. Branswyck, J. Collot, P. Vicente-Hernandez, A.M. Chaze and C. Levalliant, in: Proceedings of the $2^{\text {nd }}$ european conterence on advanced materials and processes, Euromat 91, pp.124-130

9. M.C. Flemings, Met. Trans., Vol.22A, May 1991, pp.957-981

10. E.F. Emley: Continuous casting of aluminum; International Metals Reviews, June 1976, pp.75-115

11. O. D. Sherby, J.L. Lytton and J.E. Dorn, Acta Mel., 5 (1957) pp.219-227

12. S. Siraub and $W$. Blum, Scripta. Metallurgica et Materialia, 24 (1990) pp.1837-1842

13. B.Ilschner, Hochtemperaturplastizităt, Springer Verlag, Berlin 1973

14. Rappaz : Solidification processes: constitutive equations and microstructures, Mathematical modelling for materials processing, Mark Cross, Pittman and R.D. Wood, 1993, pp.67-91

15. W. Kurz and D.J. Fisher: Fundamentals of solidification, Trans. Tech.,1984

16. E. Scheil, Zeitschrift für Metallkunde, 34 (1942)

17. G.M. Pharr and M.F. Ashby, Acta Met., 31 (1983) pp.129-138 